Research Article

\title{
Grid Connected WECS with A Five Level DCMLI using PID Controller
}

\author{
G.Balaji $^{\#, 1}$, I.Gnanambal ${ }^{*, 2}$ and C.Gowrishankar ${ }^{3}$
}

\begin{abstract}
${ }^{\# 1}$ Department of Electrical and Electronics Engineering, Paavai Engineering College, Namakkal - 637 018, Tamil Nadu, India. ${ }^{* 2}$ Department of Electrical and Electronics Engineering, Govt. College of Engineering, Salem - 636011 , Tamil Nadu, India. ${ }^{3}$ PG Student, Paavai Engineering College, Namakkal - 637 018. Tamilnadu, India.
\end{abstract}

Received 8 May 2014; Accepted 2 July 2014

\begin{abstract}
This paper deals with the analysis, modeling and control system for permanent magnet synchronous generator (PMSG) based wind turbine connected to the grid. A wind energy conversion using DC-DC Buck- Boost Converter for permanent magnet synchronous generator (PMSG) based variable speed wind energy conversion system (WECS) has been proposed which is integrated with grid using five-level diode clamped multilevel (DCMLI) inverter. In this work the instantaneous values of input side current and voltage of DC-DC buck-boost converter are utilized for implementing the PID controller. The proposed work is verified by the simulation in Powersim.
\end{abstract}

Keywords: Wind Turbine, PMSG, Buck-Boost Convertor, Diode Clamped Multilevel Inverter, and PID Controller.

\section{Introduction}

An increasing demand and depletion of the fossil fuels are constant concerns for the actual electrical energy industry [9]. In addition, the high levels of pollution due to decades of using carbon derived fuels as principal source of energy have become a major concern. In this situation, wind energy conversion has become an important source of renewable energy and the source with the biggest growth in the last decade.

The renewable energy sources can be integrated with distribution network in various multi-string topologies [9]. In variable speed wind turbine technologies, the permanent magnet synchronous generator (PMSG) has received increased attention because of its operation at high power factor, high efficiency and increased reliability due to its self excitation property in [5]. Moreover, the wind turbine is directly connected with the PMSG machine eliminating the need of a gearbox. It provides less maintenance and high reliability. A system of a variable-speed wind energy system, especially in small capacity PMSG wind system [4], consists of a rectifier, a dc-dc boost converter and a grid connected converter. The grid-connected converters are integrated with the distribution of network to regulate the power flow or optimize the power factor by controlling active and reactive power exchange to grid using the control techniques such as synchronous frame, hysteresis based strategies [6]. Typically, a two-level VSC have been used to integrate the renewable energy source with the grid. In recent developments in power electronic circuit topologies and control strategies, renewable energy systems have become economically a viable solution [8].

*E-mail address: rahullaagi@gmail.com ISSN: $1791-2377$ @ 2014 Kavala Institute of Technology. All rights reserved.
Multilevel converters provide significant advantages over the two-level converter, but not limited to lower harmonic distortion, lower electro-magnetic interference, low stress of the semiconductor switching devices and high efficiency [11]. In a control strategy (PID) for a Buck-Boost converter [21] and five-level diode Clamped Multilevel Converter integrating PMSG to a grid was proposed [21]. Moreover, a multilevel control strategy was proposed for three-phase three-level grid-connected converter based wind energy system where the external level controller was responsible to determine the active and reactive power exchange to grid. However, an increase in the number of levels of the conventional multilevel converters increases the complexity in controlling [13].

In this paper, a cascaded control strategy of five level diode clamped multilevel inverter for wind energy applications to exchange active and reactive power to grid is discussed. The required number of output voltage levels is achieved by regulating the voltage reference level, which is of great importance for reduced cost and can be used for real time. The model of the wind turbine only based on the wind speed and the pitch angle. The circuit topology and control method of the wind power generating system is investigated with a PMSG and a back-to-back ac-dc-ac power converter.

This paper is organized in the following way. The maximum power extraction of wind turbine and PMSG modeling is discussed in section II. In Section III, the circuit topology and PID control of the buck-boost converter and uncontrolled rectifier. The operation principles of Diode Clamped Multilevel Inverter are presented in section IV. In Section V, the simulation results for the proposed system. The advantage and performance evaluation of the considered wind energy system configuration is discussed in section VI and finally conclusions are summarized in section VII. 


\section{Wind Turbine and PMSG Modeling}

\section{Modeling of Wind Turbine}

Wind results from air in motion due to pressure gradient that is caused by the solar energy irradiating the earth. Wind possesses energy by virtue of its motion [8]. Any device capable of slowing down the mass of moving air can extract part of the energy and convert into useful work [5].

Wind mills or turbines works on the principle of converting kinetic energy of the wind in to mechanical energy [14].

Available power $=\frac{1}{2} \rho A V^{3}$

Where,

$\rho$ - Air density $1.225 \mathrm{~kg} / \mathrm{m}^{3}$ at sea level. (Changes by 10 to $15 \%$ due to temperature and pressure variations)

A - Area swept by rotor blade $=\Pi D^{2}$ sq-m.

$\mathrm{V}-$ Wind velocity $\mathrm{m} / \mathrm{sec}, \mathrm{D}-$ Blade diameter.

Air density, which linearly affects the power output at a given speed, is a function of altitude, temperature and barometric pressure [9]. Variation in temperature and pressure can affect air density up to $10 \%$ in either direction. Warm climate reduces air density [10].

This equation 1 tells us that maximum power available depends on rotor diameter. The combined effects of wind speed and rotor diameter can be observed by the figure 1 . This figure indicates that wind machines should have large rotors and should be located in areas of high wind speeds [14].

In practical, wind turbines are able to convert only a fraction of available wind power into useful power.

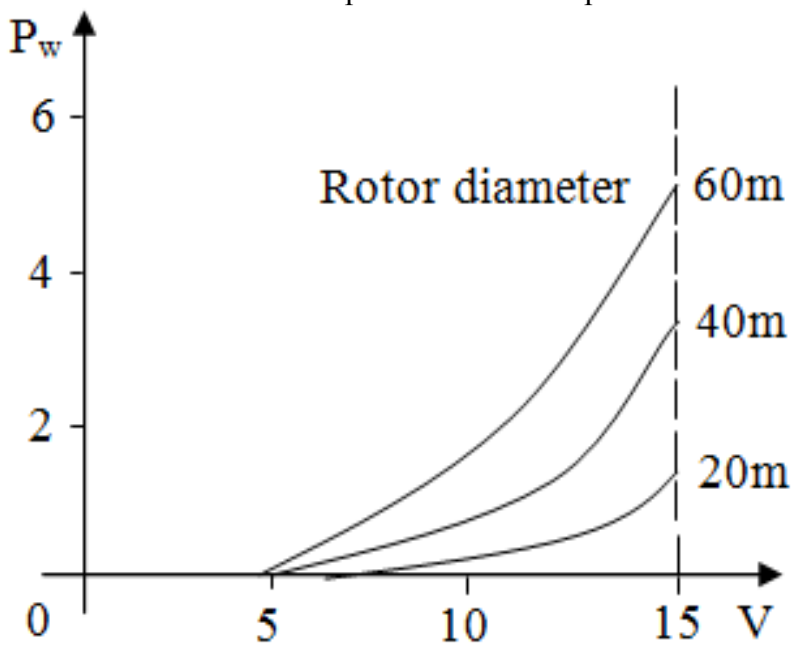

Fig. 1. Wind Speed $V_{s}$ Wind Power

As the free wind stream passes through the rotor, it transfers some of its energy to the rotor and its speed decreases to a minimum in the rotor wake [18]. After some distance from the rotor wind stream regains its speed from the surrounding air.
Wind

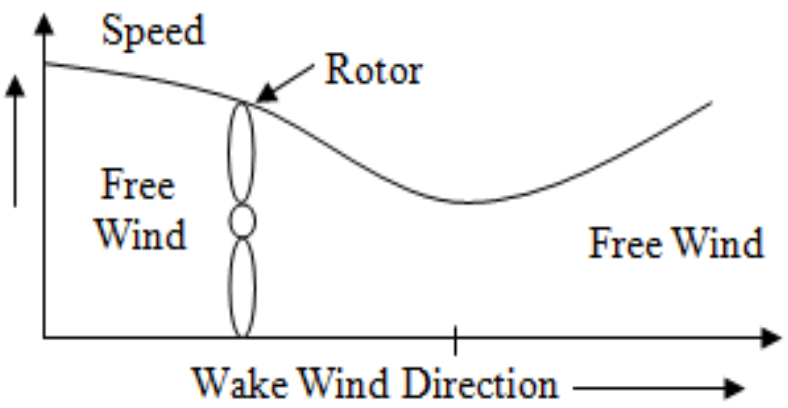

Fig. 2. Wind direction $v_{s}$ Wind Speed

We can also observe drop in pressure as the wind stream passes through the rotor. Finally air speed and pressure increases to ambient atmospheric condition. This is illustrated in the figure 2 and 2a.Pressure

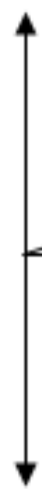

Fig. 2a. Air Speed and Pressure Increases to Ambient Pressure

\section{Modeling PMSG}

The dynamic equations of three-phase PMSG in machine without saliency in d-q synchronous frame can be written as follows:

\section{Generator mode:}

As the PMSG machine is operated in generator mode [4] and [20], so the current in the stator winding will be in opposite direction.

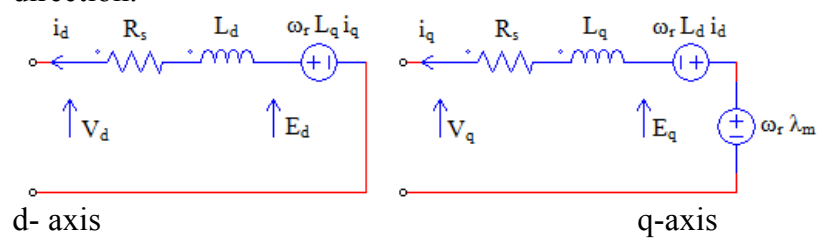

Fig. 3. d-q Frame Equivalent Circuit Diagram of the (PMSG).

According to the d-q plan, Figure 3 shows the equivalent diagram of the PMSG in generator mode. By incorporating this current direction, the voltage equations in generator mode can be written as follows:

$$
\begin{aligned}
& V_{d}=-R_{s} i_{d}-L_{d} \frac{d i_{d}}{d t}+\omega_{r} L_{q} i_{q} \\
& V_{q}=-R_{s} i_{q}-L_{q} \frac{d i_{q}}{d t}+\omega_{r} L_{d} i_{d}+\omega_{r} \lambda_{m}
\end{aligned}
$$


The e.m.f $E_{d}$ and $E_{q}$ on the $d$ and $q$ axis respectively are expressed by:

$\mathrm{E}_{\mathrm{d}}=\omega_{\mathrm{r}} \mathrm{L}_{\mathrm{q}} \mathrm{i}_{\mathrm{q}}$

$E_{\mathrm{q}}=-\omega_{\mathrm{r}} \mathrm{L}_{\mathrm{d}} \mathrm{i}_{\mathrm{d}}+\omega_{\mathrm{r}} \lambda_{\mathrm{m}}$

The mechanical power developed is expressed as:

$\mathrm{P}_{\mathrm{m}}=\frac{3}{2} \omega_{\mathrm{r}}\left(\lambda_{\mathrm{m}} \mathrm{i}_{\mathrm{q}}+\mathrm{i}_{\mathrm{d}} \mathrm{i}_{\mathrm{q}}\left(\mathrm{L}_{\mathrm{q}}-\mathrm{L}_{\mathrm{q}}\right)\right)$

The electromagnetic torque $T_{e}$ developed is expressed as:

$\mathrm{T}_{\mathrm{e}}=\frac{\mathrm{P}}{2} \frac{\mathrm{P}_{\mathrm{m}}}{\omega_{\mathrm{r}}}=\frac{3}{2}\left(\frac{\mathrm{P}}{2}\right)\left(\lambda_{\mathrm{m}} \mathrm{i}_{\mathrm{q}}+\left(\mathrm{L}_{\mathrm{q}}-\mathrm{L}_{\mathrm{q}}\right) \mathrm{i}_{\mathrm{d}} \mathrm{i}_{\mathrm{q}}\right)$

In permanent magnet machines, the smooth rotor, the reluctance is equal along the axis " $\mathrm{d}$ " and the axis "q". Substituting $\mathrm{L}_{\mathrm{q}}=\mathrm{L}_{\mathrm{d}}$ into equation (7), the equation becomes:

$\mathrm{T}_{\mathrm{e}}=\frac{3}{2}\left(\frac{\mathrm{P}}{2}\right) \lambda_{\mathrm{m}} \mathrm{i}_{\mathrm{q}}$

The electromagnetic torque $T_{e}$ is directly proportional to stator current along ' $\mathrm{q}$ ' axis $\left(\mathrm{i}_{\mathrm{q}}\right)$, and the electromagnetic torque to stator current along ' $q$ ' axis $\left(i_{q}\right)$, so the electromagnetic torque can be controlled by controlling this current.

As the turbine is connected directly to the PMSG, the dynamic equation of the PMSG is given by:

$\mathrm{J} \frac{\mathrm{d} \omega_{\mathrm{r}}}{\mathrm{dt}}=\mathrm{T}_{\text {mech }}-\mathrm{T}_{\mathrm{e}}$

Where,

$\mathrm{J}$ is the total constant inertia of wind turbine and $\mathrm{T}_{\text {mech }}$ is the mechanical torque.

The reference current along the axis ' $\mathrm{q}$ ' is found to be:

$$
\mathrm{i}_{\mathrm{e}}^{\prime}=\frac{4}{3}\left(\frac{\mathrm{T} / \mathrm{e}}{\mathrm{P} \cdot \lambda_{\mathrm{m}}}\right)
$$

The reference $\mathrm{T}^{\prime}{ }_{\mathrm{e}}$ is estimated from the speed regulation.

\section{Rectifier and DC-DC Converter Topology}

The basic principle of the buck-boost converter is fairly simple (see figure): While in the On-state, the input voltage source is directly connected to the inductor (L). This results in accumulating energy in L. In this stage, the capacitor supplies energy to the output load.

$>\quad$ While in the Off-state, the inductor is connected to the output load and capacitor, so energy is transferred from $\mathrm{L}$ to $\mathrm{C}$ and R.Compared to the buck and boost converters, the characteristics of the buck-boost converter are mainly:

$>$ Polarity of the output voltage is opposite to that of the input, the output voltage can vary continuously from 0 to $-\infty$ (for an ideal converter). $>\quad$ The output voltage ranges for a buck and a boost converter are respectively 0 to $\mathrm{V}_{\mathrm{i}}$ and $\mathrm{V}_{\mathrm{i}}$ to $\infty$.

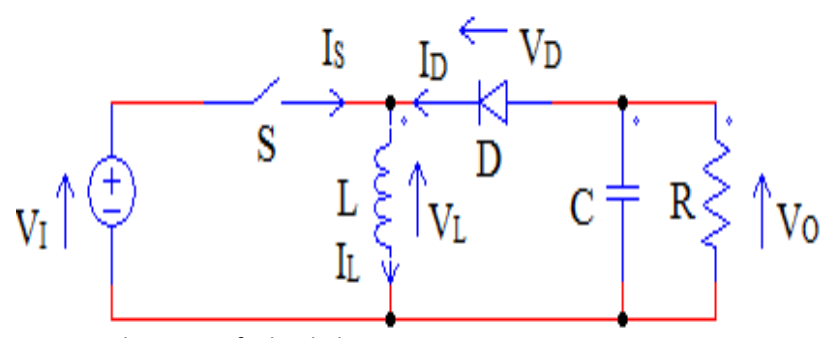

Figu 4. Schematic of a buck-boost converter

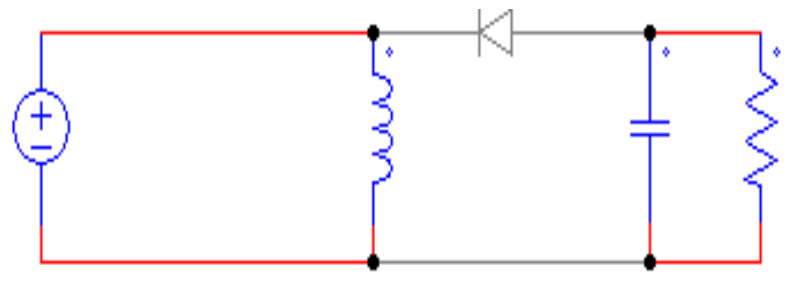

Fig 4a. The two operating states of a buck-boost converter:

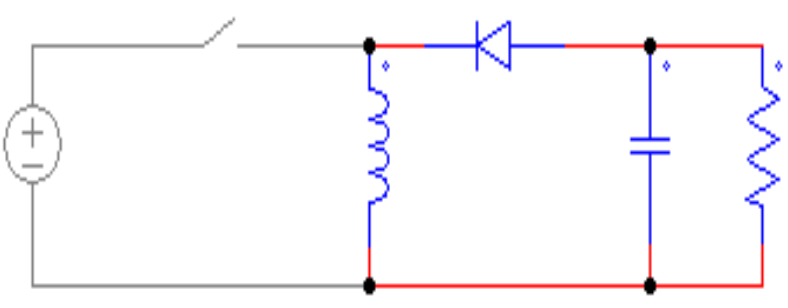

Fig. 4 b. When the switch is open.

When the switch is turned-on, figure (4a) the input voltage sources supplies current to the inductor, and the capacitor supplies current to the resistor (output load). The inductor supplies current to the load via the diode figure (4b). The buck-boost converter is operated in both continuous and discontinuous mode as shown in figure (5 and 6). The following formulas are used to design the converter.

\section{Buck-Boost Parameter}

Inductor $L=\frac{n(1-k) R}{2 f}=202 \eta H$

Capacitor $\mathrm{C}=\frac{\mathrm{k}}{2 \mathrm{fR}}=120 \eta \mathrm{f}$

Vo $=\frac{\text { Vs } \alpha}{1-\alpha}=300$ volt

$\alpha=\frac{\text { Ton }}{\text { Vs }}=0.5 \mathrm{~ms}$

Ton $=\alpha \mathrm{T}$

$\mathrm{T}=\frac{1}{\mathrm{f}}$

Switching Frequency $=10000 \mathrm{HZ}$ 


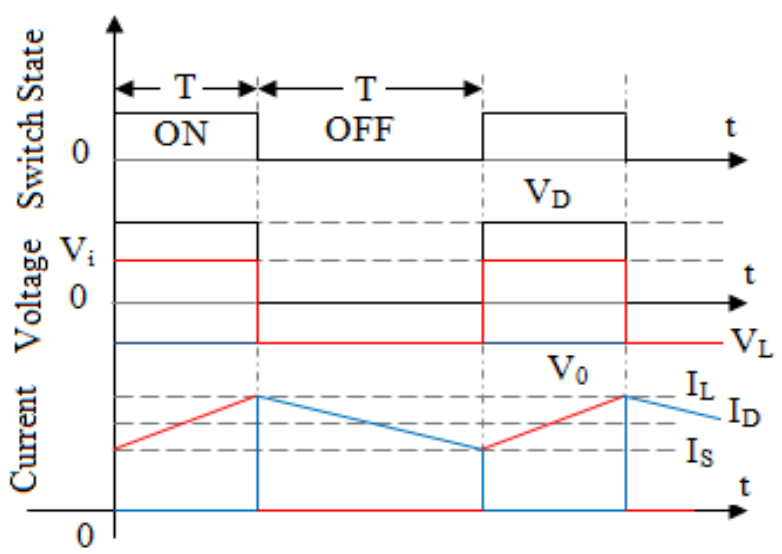

Fig. 5. Waveforms of current and voltage in a buck-boost converter operating in continuous mode.

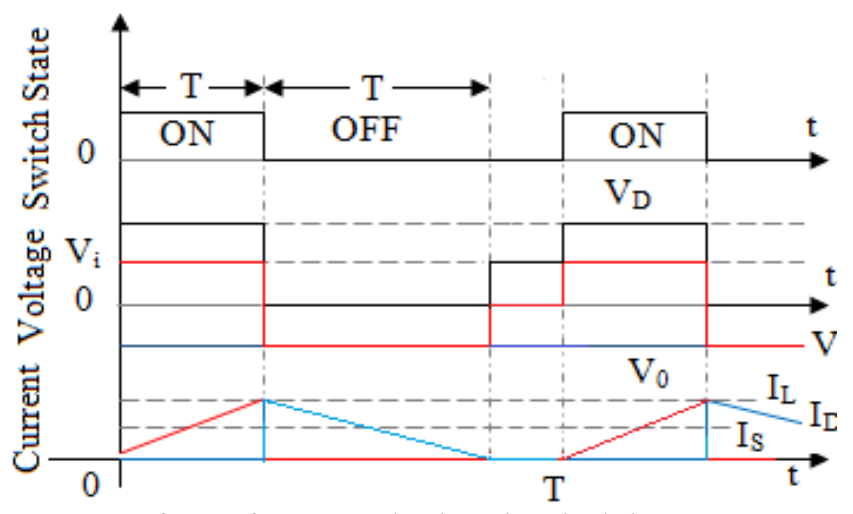

Fig. 6. Waveforms of current and voltage in a buck-boost converter operating in discontinuous mode.

\section{Circuit, Simulation and Result Analysis, Discssion}

Now days the energy demand is increasing day by day. In order to compensate or increasing energy production we move to renewable energy. Here, the wind energy is converted into mechanical energy by using wind turbine. Wind energy is capable of supplying large amounts of power but its presence is highly unpredictable as it cannot be obtained at same level of wind energy, it differs in each region. To describe a wind turbines power characteristic, equation describes the mechanical power that is generated by the wind.

$P_{m}=0.5 \rho A C_{p}(\lambda, \beta) V^{3}$

Where,

$\rho=$ air density,

$\mathrm{A}=$ rotor swept area,

$\mathrm{C}_{\mathrm{p}}(\lambda, \beta)=$ power coefficient function

$\lambda=$ tip speed ratio,

$\beta=$ pitch angle,

$\mathrm{V}=$ wind speed

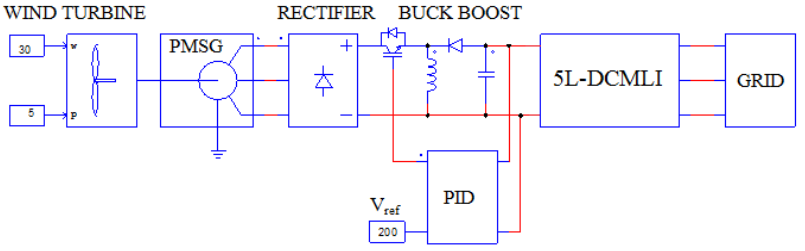

Fig. 6. Circuit Diagram of the Proposed System

The power coefficient $(\mathrm{Cp})$ is a nonlinear function that represents the efficiency of the wind turbine to convert wind energy into mechanical energy. But, for a given turbine $\mathrm{Cp}$ is not always constant. The most common parameters for $\mathrm{Cp}$ are the tip speed ratio $\lambda$ and the pitch angle $\beta$. The TSR, $\lambda$, refers to a ratio of the turbine angular speed over the wind speed. The mathematical representation of the TSR is given by $\lambda$. The pitch angle, $\beta$, refers to the angle in which the turbine blades are aligned with respect to its longitudinal axis.

This mechanical energy is converted into electrical energy using a generator. The PMSG is used here because it has been gaining a lot of attention for WECS because of the following reasons compact size, higher power density, reduced losses, high reliability and robustness. Moreover, there is a need of low-speed gear less generator, especially for off-shore wind applications.

$\lambda=\frac{\text { tip speed }}{\text { wind speed }}=\frac{\mathrm{R} \omega_{\mathrm{b}}}{\mathrm{V}}$

Where,

$\mathrm{R}=$ turbine radius,

$\omega \mathrm{b}=$ angular rotational speed

Both the brushes and the gear box can be eliminated from WECS by using directly coupled low speed generators. Further, the elimination of the gear box can increase the efficiency of wind turbine by $10 \%$.Another advantage is maintenance free operation since there are no brushes.

The Proposed circuit shown in figure 4.1, the electrical energy fed into the diode rectifier is given to the buck boost converter. The buck boost converter can be operated in the buck mode or boost mode using PID controller. The output of buck boost converter is given to the input of five level diode clamped multi level inverter. The multi level inverter operates when number of levels is high enough, the harmonic content is low enough to avoid the need for filters. Inverter efficiency is high because all devices are switched at the fundamental frequency and control method is simple.

\section{Parameter Design}

a) Turbine Parameter and PMSG parameter

Wind turbines power characteristic, equation describes the mechanical power that is generated by the wind. Table 5.1 and 5.2 shows the wind turbine and PMSG parameter.

$P_{m}=0.5 \rho A C_{p}(\lambda, \beta) V^{3}$

Where,

$\rho=$ air density, 
$\mathrm{A}=$ rotor swept area,

$\mathrm{C}_{\mathrm{p}}(\lambda, \beta)=$ power coefficient function

$\lambda=$ tip speed ratio,

$\beta=$ pitch angle,$\left(5^{\circ}\right)$

$\mathrm{V}=$ wind speed

Table 2. Wind Turbine Parameter

\begin{tabular}{l|c}
\multicolumn{1}{c|}{ PARAMETERS } & VALUE \\
\hline Nominal Output Power & 1000 \\
Base Wind Speed & 9 \\
Base Rotational Speed & 20 \\
Initial Rotational Speed & 0 \\
Moment of Inertia & 0.0002 \\
\hline
\end{tabular}

Table 3. PMSG parameter

\begin{tabular}{l|c}
\multicolumn{1}{c|}{ PARAMETERS } & VALUE \\
\hline Voltage Rating (Volts) & $400 \mathrm{~V}$ \\
Current Rating (I) & $20 \mathrm{~A}$ \\
Power Rating (Watts) & $8 \mathrm{KW}$ \\
Speed Rating (N) & $1500 \mathrm{rpm}$ \\
Stator Resistance $\left(\mathrm{R}_{\mathrm{S}}\right)$ & $4.3 \Omega$ \\
d-axis Inductor $\left(\mathrm{L}_{\mathrm{d}}\right)$ & $0.027 \mathrm{H}$ \\
q-axis Inductor $\left(\mathrm{L}_{\mathrm{q}}\right)$ & $0.067 \mathrm{H}$ \\
Number of Poles $(\mathrm{P})$ & 6 \\
Moment of Inertia & 0.00179 \\
Mechanical Time Constant & 10 \\
\hline
\end{tabular}

\section{b) Buck-Boost Parameter}

Inductor $\mathrm{L}=\frac{\mathrm{n}(1-\mathrm{k}) \mathrm{R}}{2 \mathrm{f}}=202 \eta \mathrm{H}$

Capacitor $\mathrm{C}=\frac{\mathrm{k}}{2 \mathrm{fR}}=120 \eta \mathrm{f}$

Vo $=\frac{\text { Vs } \alpha}{1-\alpha}=300$ volt

$\alpha=\frac{\text { Ton }}{\text { Vs }}=0.5 \mathrm{~ms}$

Ton $=\alpha \mathrm{T}$

$\mathrm{T}=\frac{1}{\mathrm{f}}$

Switching Frequency $=10000 \mathrm{HZ}$

\section{Simulation Results}

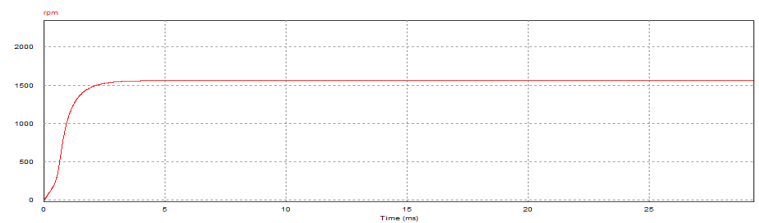

Fig. 7a. Speed Waveform for the Generator

In the above figure 7 shows the generator speed waveform which are measured by voltage probe.

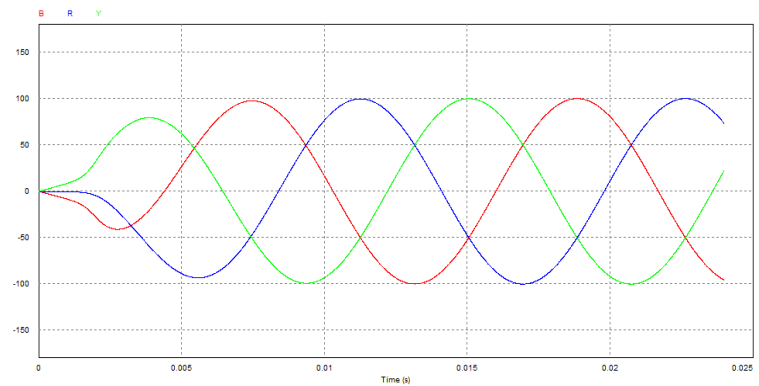

Fig. 7b. PMSG Output Waveform

The wind turbine will rotate at $1200 \mathrm{rpm}$. The wind turbine shaft is directly coupled with the permanent magnet synchronous generator (PMSG) through mechanical coupling. Here, the wind (kinetic) energy is converted as mechanical energy.

In this figure $7 \mathrm{~b}$ shows the output waveform of PMSG which gives the three phase voltage waveform. Here, the PMSG is converting the mechanical energy to Electrical energy.

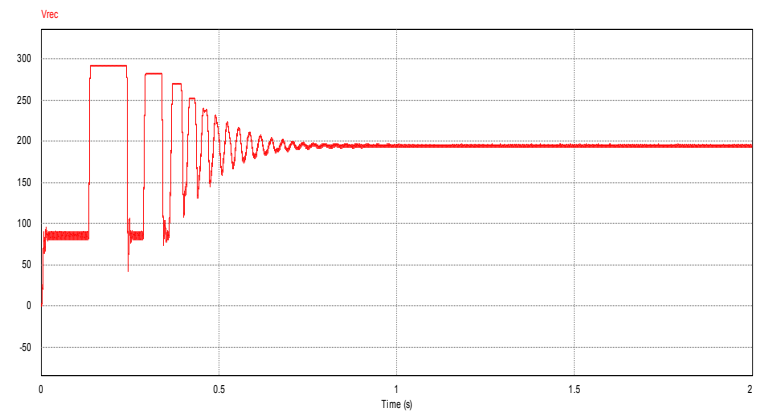

Fig. 8. Output Voltage Waveform of Rectifier

Here, the three phase diode bridge rectifier is used to convert the AC source to DC supply. In the figure 8 shows the output waveform of uncontrolled rectifier. The generated three phase AC source is connected to uncontrolled rectifier to convert as a DC source.

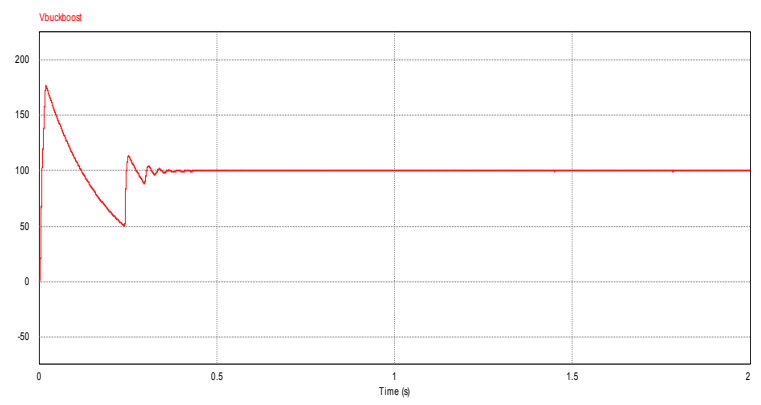

Fig. 9. Voltage Waveform of Buck-Boost Converter in Buck Mode

The figure 9 shows the output voltage waveform of buck-boost (DC-DC) converter in buck mode with PID controller.

The figure 10 shows the output voltage waveform of buck-boost (DC-DC) converter in boost mode with PID controller. The converter will perform to produce constant 
output with the help of increasing or decreasing the input of the buck-boost for our required level.

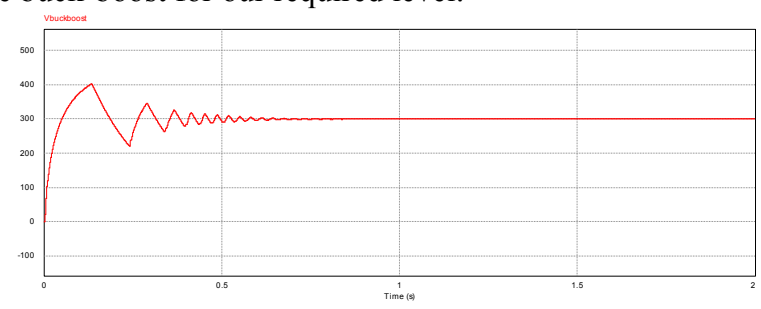

Fig. 10. Voltage Waveform of Buck-Boost Converter in Boost Mode

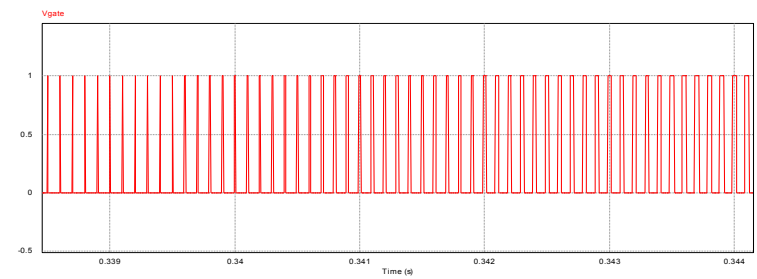

Fig. 11. Switch Gate Pulse of Buck-Boost Converter in Boost Mode

In the above figure 11 shows the switching gate pulse of Buck-Boost Converter in Boost Mode.

The switching gate pulse will vary depending on the error signal produced in the system. If the error is low the switch ON time is low and OFF time is high compared to ON time, when the error signal is high, switch gate pulse ON time is increased as well as OFF time is reduced.

In the figure 12 shows the switching gate pulse of BuckBoost Converter in Boost Mode. The switching gate pulse will vary depending on the error signal produced in the system.

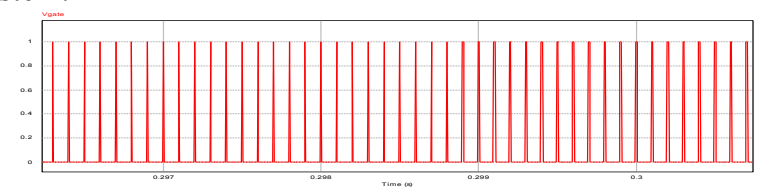

Fig. 12. Switching Gate Pulse of Buck-Boost Converter in Buck Mode

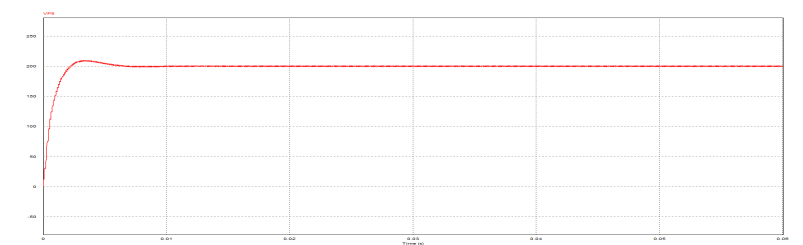

Fig. 13. Input Voltage Waveform of Multilevel Inverter
The figure 13 shows the input waveform of the DCML inverter. The input is constant with the help of PID controller, so the system produces constant output.

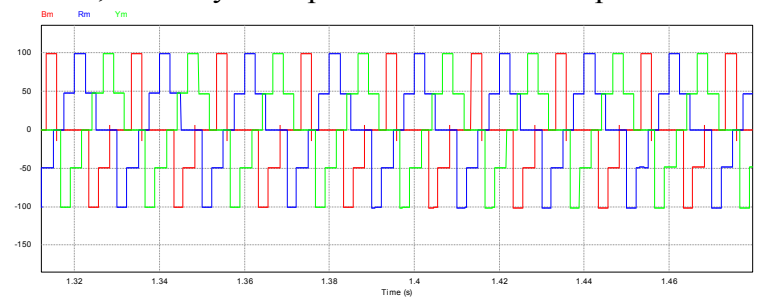

Fig 14. Output voltage waveform of DCMLI with RL load

The output of buck boost converter is given to the input of the five level diode clamped multilevel inverter. The multilevel inverter is inverting the input $\mathrm{DC}$ to $\mathrm{AC}$ for our required grid connected level shown in figure 14. It does not require an output filter because high-order harmonics are effectively filtered off, owing to the reactance of the inductive load; therefore, it can produce a staircase voltage waveform with lower harmonics eliminated such that higher order harmonics can be easily filtered.

\section{Conclusion}

In this work the simulation results of wind energy conversion system with three phase five level diode clamped multilevel inverter are obtained through Powersim for grid application. High-efficiency converters are desirable for renewable energy systems, specifically those related with grid connected wind applications. The aim is to have a simple, robust, free maintenance, and highly efficient system. The proposed five-level DCMLI has been applied in a three phase wind energy system and presents several promising advantages. First, it can generate power for ac utility from PMSG. Secondly, it increases or decreases output-voltage level with the help of buck-boost converter to maintain constant output so that it has higher efficiency and lower weight for the overall system. Third, in the case of a five-level multilevel inverter, it does not require an output filter because high-order harmonics are effectively filtered off, owing to the reactance of the inductive load; therefore, it can produce a staircase voltage waveform with lower harmonics eliminated such that higher order harmonics can be easily filtered off if needed for that particular application. Finally, it reduces stresses on power switching devices, resulting in low audio and radio-frequency (RF) noise, EMI, or less electromagnetic compatibility problems, because the multilevel inverter operates with a low switching frequency.

\section{References}

1. Akira Nabae, Isao Takahashi, and Hirofumi Akagi, (1981) “A New Neutral-Point-Clamped PWM Inverter," IEEE Transactions on Industry Applications, Vol. IA-17, No. 5.

2. Benadja M, and Ambrish Chandra, (2012) "A New MPPT Algorithm for PMSG Based Grid Connected Wind Energy System with Power Quality Improvement Features," IEEE Transactions.

3. Belakehal S, Benalla $\mathrm{H}$ and Bentounsi A, (2009) "Power maximization control of small wind system using permanent magnet synchronous generator," Revue des Energies Renouvelables Vol. 12.

4. Benelghali S, Benbouzid M.E.H and Charpentier J.F, (2010) "Comparison of PMSG and DFIG for Marine Current Turbine Applications," International Conference on Electrical Machines ICEM, Rome.

5. David Green, Eric Gill, and Weimin Huang, (2009) "An Inversion Method for Extraction of Wind Speed From HighFrequency Ground-Wave Radar Oceanic Backscatter," IEEE 
Transactions on Geoscience and Remote Sensing, Vol. 47, NO. 10 .

6. JorgMeili, SrinivasPonnaluri, Leonardo Serpa, Peter K. Steimer, Johann W. Kolar, (2006), "Optimized Pulse Patterns for the 5Level ANPC Converter for High Speed High Power Applications," IEEE Transactions.

7. Jose Rodríguez, Steffen Bernet, BinWu, Jorge O. Pontt, and Samir Kouro, (2007) "Multilevel Voltage-Source-Converter Topologies for Industrial Medium-Voltage Drives," IEEE Transactions on Industrial Electronics, Vol. 54, NO. 6.

8. Lars Helle and StigMunk-Nielsen, (2001) "Comparison of Converter Efficiency in Large Variable Speed Wind Turbines," IEEE Transactions.

9. Marco Liserre, Remus Teodorescu, and FredeBlaabjerg, (2006) "Stability of Photovoltaic and Wind Turbine Grid-Connected Inverters for a Large Set of Grid Impedance Values," IEEE Transactions on Power Electronics, Vol. 21, NO. 1.

10. Mario Marchesoni, Maurizio Mazzucchelli, and SandroTencon, (1990) "ANonconventional Power Converter for Plasma Stabilization," IEEETransactions on Power Electronics. Vol. 5.

11. MeynardT.AandFoch H, (1992) "Multi-Level Conversion: high Voltage Choppers and Voltage-Source Inverters," IEEE Transactions.

12. Peter Steimer, Peter Barbosa, Jürgen Steinke, Manfred Winkelnkemper, and Nikola Celanovic, (2005) "Active-NeutralPoint-Clamped (ANPC) Multilevel Converter Technology,”EPE - Dresden.

13. Prasad E, Sudhakar A, and VijayKumar, (2012) "Simulation of five-level inverter fed PMSM based on fast SVPWM," IEEE International Conference on Power Electronics, Drives, Bengaluru, India.

14. Quincy Wang, and Liuchen Chang,(2004) “An Intelligent Maximum Power Extraction Algorithm for Inverter-Based Variable Speed Wind Turbine Systems," IEEE Transactions on Power Electronics, Vol. 19.

15. Rahul Sharma, Bagh S.K, and Sandeep Banerjee, (2012), “A Novel Approach of Grid Connected Wind Energy Conversion System with Modified Maximum Power Point Tracking,'IEEE International Conference on Power Electronics, Drives and Energy Systems Bengaluru, India

16. Roshankumar P, Rajeevan P.P, Mathew K, Gopakumar K, Jose I. Leon, and LeopoldoFranquelo G, (2012), "A Five-Level Inverter Topology with Single-DC Supply by Cascading a Flying Capacitor Inverter and an H-Bridge," IEEE Transactions on Power Electronics, Vol. 27, No. 8.

17. Samir Kouro, Mariusz Malinowski, K. Gopakumar, JosepPou, Leopoldo G. Franquelo, BinWu, Jose Rodriguez, Marcelo A. Pérez, and Jose I. Leon,(2010), "Recent Advances and Industrial Applications of Multilevel Converters," IEEE Transactions on Industrial Electronics, Vol. 57, No. 8.

18. Shyam B, Aswathy B. Raj and Robins Anto, (2011), "PMG Based Wind Energy Conversion System with Closed Loop Boost Converter," Bonfring International Journal of Power Systems and Integrated Circuits, Vol. 1.

19. Sridhar R. Pulikanti, KashemMuttaqi and Danny Suntanto, (2012) "Control of Five-level Flying Capacitor Based ActiveNeutral-Point-Clamped Converter for Grid Connected Wind Energy Applications," IEEE Transactions.

20. Zaijun $\mathrm{Wu}$, Xiaobo Dou, Jiawei Chu and Minqiang Hu, (2013), "Operation and Control of a Direct-Driven PMSG-Based Wind Turbine System with an Auxiliary Parallel Grid-Side Converter," Energies.

21. Zheng Zhao, Ming Xu,Qiaoliang Chen, Jih-Sheng (Jason) Lai, and Younghoon Cho, (2012), "Derivation, Analysis, and Implementation of a Boost-Buck Converter-Based HighEfficiency PV Inverter," IEEE Transactions on Power Electronics, Vol. 27. 